\section{A SPOONFUL OF SYRUP}

In the US there are over 800 over-thecounter medications for treating the common cold, and there are probably a similar number in European countries. Most parents set great store but paediatricians are sceptical.

Prejudice is all very well, but evidence is all the rage nowadays so we are pleased to publish Schroeder and Fahey's systematic review of RCTs of over the counter medicines for acute cough. It is instructive to look at their figure 1, detailing what must have been a pretty depressing journey through the literature: they immediately triaged 235 of 328 identified trials as inadequate and excluded a further 87 after review. Just six RCTs remained, all less than totally methodologically sound. For what they were worth, their results do not show any benefit of cough medicines over placebo.

Once again, the pointlessness of so many peer reviewed published papers is shown up, not that this will reduce the relentless increase in submissions from hopeful authors. Readers who are parents of small children might take some heart from the latest edition of Nelson Textbook of Pediatrics, [1] which has a soft spot for tea with lemon and honey and chicken soup (presumably separately rather than together), but reports no RCT to back up the claim.

See page 170

\section{DOCTOR KNOWS BEST}

What about medication for which evidence of efficacy is high-namely inhaled beta-agonists and corticosteroids for asthma? Not all is well. Dr Child and

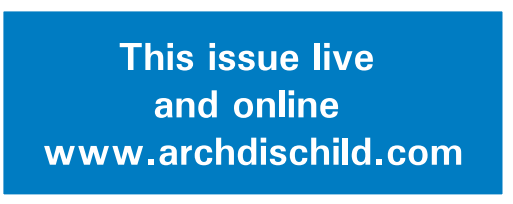

colleagues looked at the appropriateness of prescriptions for inhaler devices using as their gold standard the British Thoracic Society guidelines. They describe their findings as "not encouraging": for example, over one third were using an unsuitable device; and many children prescribed metered dose inhalers by their general practitioners-including 17\% of those aged under 5 years-were not provided with a spacer.

Before the results were known, the authors believed they had a successful local GP and paediatrician asthma group but now state: "We now realise that, in relation to inhaler use, this has failed". We paraphrase Nurse Edith Cavell: "Guidelines are not enough".

See page 176

\section{OK, HOW ABOUT PARENTS KNOW BEST?}

The German Infant Nutritional Intervention (GINI) programme included conducting an RCT of different modified formula feeds to reduce or prevent symptoms in children at risk of atopy. Over two thousand families were recruited and randomised, the formula being provided free of charge and, among other advice, it was recommended that infants did not have solid food for their first four months, following which one food at a time could be introduced.

Schoetzau and colleagues report how compliant parents were with the conditions imposed by the trial. One in 7 families dropped out before completion, mostly because their child was experiencing one or more of the common minor digestive problems of infancy. Of the remainder, $83.4 \%$ complied with milk feeding recommendations. The temptation to add solids was too strong for nearly 35\%. Not surprisingly, non-compliers were more likely to be young, less well educated, non-native to the country and smokers.

The authors recommend that research on efficacy must go hand in hand with that on compliance. This means keeping the burden of any programme as low as possible and identifying in advance those parents who need extra encouragement to stick to the rules.

See page 180

\section{ARE HEALTH VISITORS THE ANSWER?}

For more than 10 years, three deprived areas of a city in southwest England subscribed to the First Parent Health Visitor Scheme (FPHVS). First time parents received a programme of 5-weekly visits from a specially trained health visitor (with nursing qualifications) to support and advise them in dealing with their new child. An evaluation of the scheme, compares outcomes with families who received the much less intensive health visiting programme common throughout the National Health Service.

The FPHVS seems to have been successful in producing a higher rate of breast feeding by 1 year (OR 2.08, 95\%CI 1.11-3.91) and a greater attention by parents to safety, in terms of lower accident rates. Developmental outcome, immunisation rates, uptake of child health surveillance, and use of hospital services were unaffected. However, FPHVS mothers consulted their general practitioner less frequently, neatly balancing the cost of the extra health visitor involvement.

Overall, the authors were unable to show many clear advantages of the scheme although speculate whether improved parental confidence might show benefits when the children are older.

See page 150 